\title{
DESIGN AND OPTIMIZATION OF A GAS TURBINE REGENERATOR WITH FIXED PRESSURE DROP USING GA AND FIREFLY ALGORITHMS
}

\author{
NAVID BOZORGAN \\ Department of Mechanical Engineering, Dezful Branch, Islamic Azad University, Dezful, Iran \\ AshKan GHAFOURI \\ Department of Mechanical Engineering, Ahvaz Branch, Islamic Azad University, Ahvaz, Iran \\ e-mail: a.ghafouri@iauahvaz.ac.ir (corresponding author) \\ EhSANOLAh AsSAREH \\ Department of Mechanical Engineering, Dezful Branch, Islamic Azad University, Dezful, Iran \\ Seyed M. Safieddin Ardebili \\ Department of Mechanical Engineering, Dezful Branch, Islamic Azad University, Dezful, Iran, and \\ Department of Biosystems Engineering, Shahid Chamran University of Ahvaz, Ahvaz, Iran
}

\begin{abstract}
The present study investigates eight design parameters such as seal coverage, core porosity, core volume ratio, core thickness, dimensionless core rotation rate, inner diameter of the core, air mass flow rate and exhaust mass flow rate to design and optimize a regenerator of a 20-MW power generation gas turbine with fixed pressure drop. The application of GA and Firefly algorithms to optimize the effectiveness of the regenerator is presented to demonstrate the efficiency and accuracy of the proposed algorithms. The effect of change in the seal coverage, core porosity, core volume ratio and dimensionless core rotation rate are evaluated as important design parameters having influence on the size and mass of the core of the regenerator. This could be done through fixing each of these parameters, while the other seven design parameters are selected as variables to optimize the effectiveness. The results show that the selection of all eight-design parameters proposed as operating variables is necessary to optimize the parameters to achieve the proper design of this regenerator.
\end{abstract}

Keywords: rotary regenerator, design and optimization, regenerator effectiveness

\section{Introduction}

A regenerator is a compact heat exchanger with a cylindrical matrix, which transfers thermal energy from a hot gas to a cold stream during cold stream flow. Recovery of waste heat from the exhaust gas by regenerators has considerably increased in recent years due to their compactness, high flexibility, efficiency and easy maintenance in cases such as power plants, thermal comfort systems and aircraft/vehicular gas turbine applications. This increases the industrial use of rotary regenerators that has attracted attention of several researchers for modeling these kinds of regenerators. The focus of many of these studies is on heat transfer and flow modeling and comparing between numerical results and experimental measurements. However, few studies have focused on the design and optimization of regenerators by considering different design variables through using advanced optimization algorithms. Akbari et al. (2018) experimentally showed a $42.2 \%$ efficiency improvement by preheating the inlet air of the air jet impingement food dryer through using a rotary regenerator as a waste heat recovery system. Sanye et al. (2008) obtained an optimum design for an air-to-air rotary regenerator with considering effectiveness as the objective function using GA. They also compared numerical optimization results with experimental data. Wang et al. (2019) optimized a rotary regenerative air preheater (RAPH) 
with a thermal hydraulic calculation program coupled with GA in a coal-fired power plant. Their results showed $26.5 \%$ reduction in the total weight of heat transfer elements when compared to the original. Mioralli and Ganzarolli (2013) evaluated performance of a regenerator at constant pressure drop to find optimal operating conditions. They determined the maximum heat transfer in an optimal porosity. Özdemir and Serincan (2018) presented a computational fluid dynamics model for evaluating the effects of different operating conditions such as angular velocity, treated gas inlet temperature and load conditions on the performance of the rotary regenerator used in a flue gas desulfurization system. Raja et al. (2016) optimized the rotary regenerator by considering six design variables using TS-TLBO algorithm. The results of their study demonstrated the accuracy and effectiveness of the proposed algorithm. Alhusseny and Turan (2016) numerically investigated the impact of different design aspects such as operating conditions, core dimensions and core geometrical characteristics on the overall regenerator effectiveness, pressure drop and the overall system performance using a porous media approach.

Chung et al. (2016) numerically optimized the aspect ratio, rotating speed, split and purge section angle of a plastic rotary regenerator considering leakage and adsorption in the desiccant air-conditioning system. Mohanty (2016) optimized a shell and tube heat exchanger by considering the investment cost and the operating cost as the objective function through using Firefly algorithm. Their results showed that the operating cost and the total cost could be reduced by $77 \%$ and $29 \%$ compared to the original design, respectively. Raja et al. (2017) minimized the total annual cost and total weight of a fin-and-tube heat exchanger by considering seven design variables using the heat transfer search (HTS) algorithm. Their results were validated with those obtained by using GA, PSO and artificial bee colony algorithms.

Rao and Patel $(2010,2013)$ carried out thermo-economic multi-objective optimization of a plate-fin heat exchanger using TLBO and PSO, respectively. Raja et al. (2018) performed thermal-hydraulic optimization of a plate heat exchanger in the form of Pareto-optimal points by considering eight geometric design variables.

Wang et al. (2018) investigated the effects of configuration parameters on the performance of a tube bundle of a spiral-wound heat exchanger (SWHE) by the Multi-Objective Genetic Algorithm. Wen et al. (2017) optimized the helix angle and overlapped degree of helical baffles of a shell-and-tube heat exchanger by the multi-objective genetic algorithm (MOGA). Wu et al. (2018) optimized the design parameters such as thickness of the spacer, axial tube spacing of the same layer and the winding angle in a spiral-wound heat exchanger by considering the total heat exchange area as the objective function.

In the present study, GA and Firefly algorithms applied to optimize eight design parameters by considering the effectiveness as the objective function in a regenerator of a 20-MW power generation gas turbine with fixed pressure drop. Next, the effect of change in the seal coverage, core porosity, core volume ratio and dimensionless core rotation rate are evaluated as important design parameters having an impact on the size and mass of the core of the regenerator.

\section{Genetic and Firefly algorithms}

Genetic Algorithm (GA) was introduced based on Darwin's theory of evolution by Holland (1975). In GA, a chromosome containing a group of genes is used to optimize design parameters. A genetic algorithm solves optimization problems by selecting a population of chromosomes which have higher fitness values.

Firefly Algorithm (FA) was proposed based on the flashing behavior of fireflies by Yang (2008). For solving an optimization problem, the brightness of a firefly is proportional to the objective function. In the formulation of FA, the firefly with the maximum light intensity will be chosen as the best solution with the higher objective function value. 


\section{Formulation of the rotary regenerator design}

Figure 1 shows a regenerative gas turbine. The present work considers a radial flow rotary regenerator with fixed pressure drop and continuous square passages (with dimensions shown in Fig. 2) used for the regenerative gas turbine. This regenerator is used to extract the heat from the exhaust gas for heating the compressed air. This compressed and pre-heated air then enters the combustors. The governing equations for design and optimization of the regenerator are listed in the following parts.
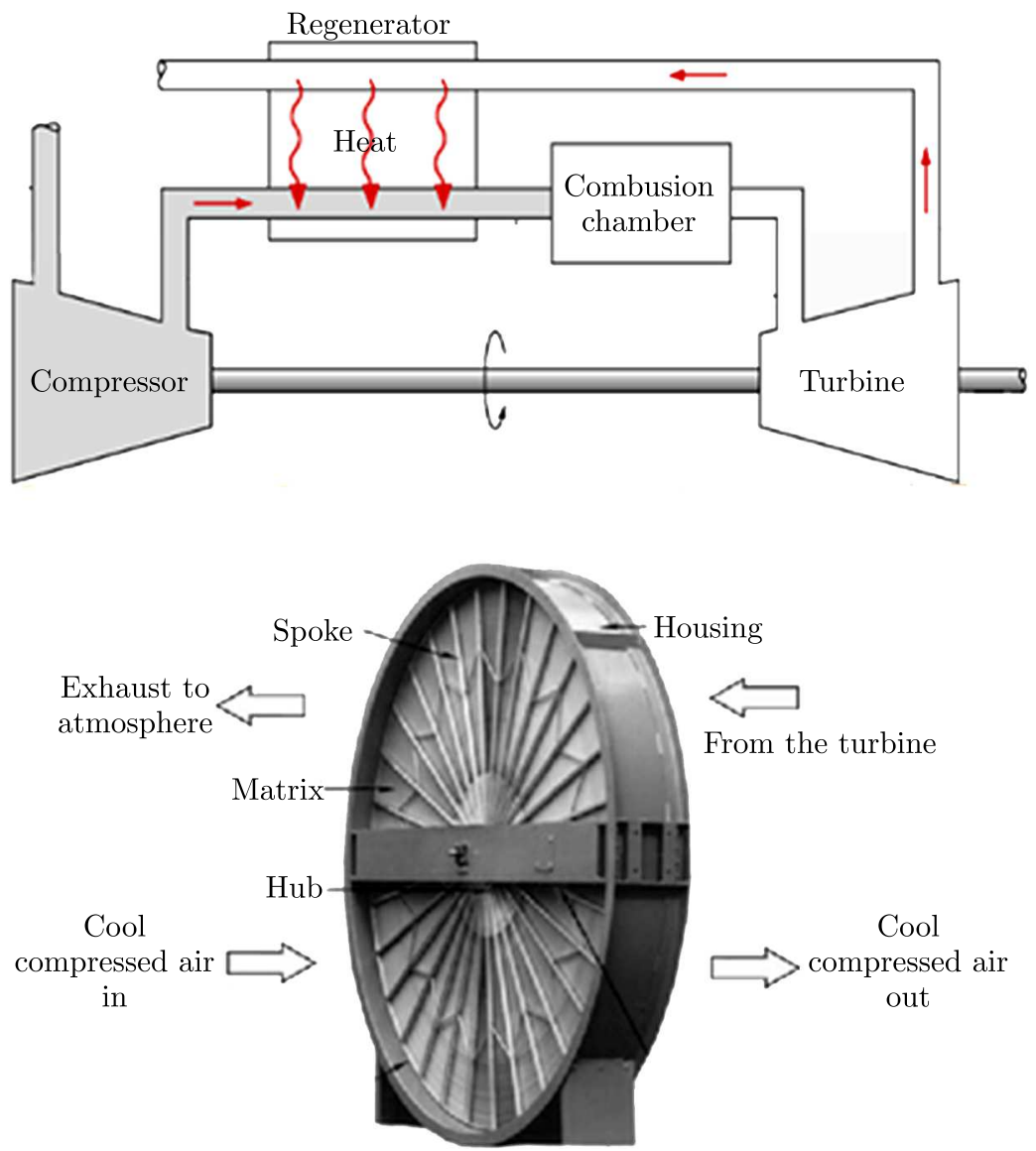

Fig. 1. Scheme of the system formed by the regenerator and turbine

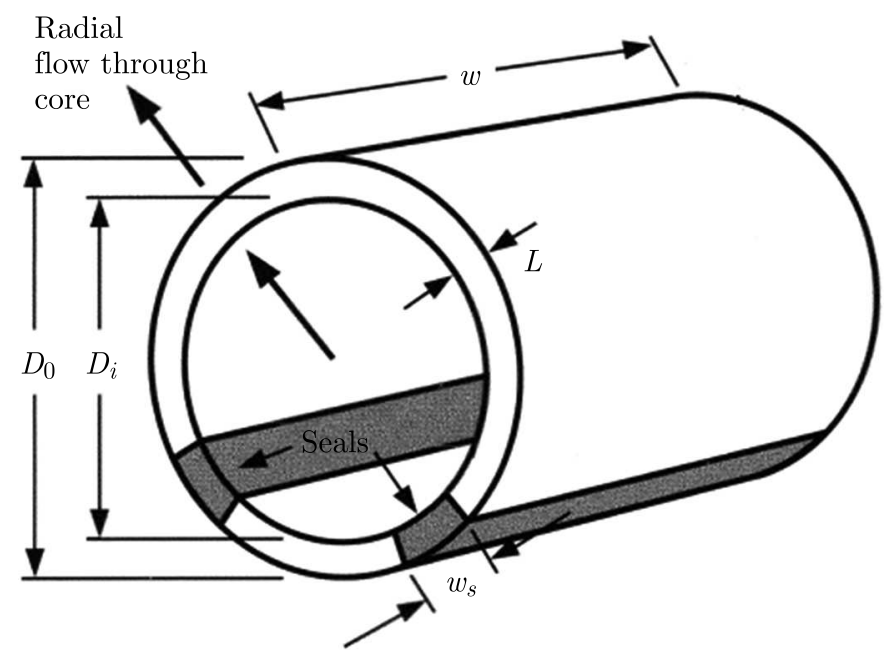

Fig. 2. Dimensions of the regenerator with radial flows 


\subsection{Geometrical parameters}

The total frontal area of the core of the regenerator is calculated as

$$
A_{t o t}=A_{X}+A_{N}+A_{S}
$$

The total frontal area of the core on the exhaust side $A_{X}$ is

$$
A_{X}=\frac{1}{p} \frac{\dot{m}_{X}}{\bar{\rho}_{X} \bar{U}_{X}}
$$

where $p$ is the core porosity and defined as the ratio of the voids volume to the total core volume, $\bar{\rho}_{X}$ is the average density on the exhaust side, $\bar{U}_{X}$ is the exhaust-side mean velocity, $\dot{m}_{X}$ is the exhaust mass flow rate.

The total frontal area of the core on the compressed-air side $A_{N}$

$$
A_{N}=V^{\prime} A_{X}
$$

where $V^{\prime}$ is the core volume ratio defined as the ratio of the core volume on the compressed-air side to the core volume on the exhaust side.

The total frontal area of the core under seals $A_{S}$

$$
A_{S}=\frac{S C}{1-S C}\left(A_{N}+A_{X}\right)
$$

where $S C$ is the fraction of the core face covered by seals.

Also the total core volume mass of the core and core width can be calculated as follows

$$
V_{R}=A_{t o t} L \quad \omega=\frac{A_{t o t}}{\pi \bar{D}} \quad \bar{D}=\frac{D_{i}+D_{o}}{2}
$$

where $L$ is the core thickness or flow length, $\bar{D}$ is the average core diameter, $D_{i}$ and $D_{o}$ are the inner and outer diameters of the core and $D_{o}=D_{i}+2 L$ for radial-flow regenerators.

Finally, the total volume under seals, seal length and seal width are calculated as follows

$$
V_{S}=A_{S} L \quad \omega_{S}=\frac{S C}{2} \pi \bar{D}
$$

and for radial-flow regenerators

$$
L_{S}=2(\omega+L)
$$

\subsection{Core rotation period}

The rotation period of the core and the average core rotation speed are calculated as follows (Beck and Wilson, 1996)

$$
\tau_{\text {rot }}=\frac{m_{R}}{\dot{m}_{R}} \quad S_{\text {core }}=\frac{\pi \bar{D}}{\tau_{\text {rot }}}
$$

where

$$
m_{R}=\rho_{R}(1-p) V_{R} \quad \dot{m}_{R}=\frac{C_{r o t} C_{N}}{c_{R}} \quad C_{N}=\frac{\dot{m}_{N}\left(i_{N o}-i_{N i}\right)}{T_{N_{o}}-T_{N i}}
$$

where $m_{R}$ is mass of the core, $\dot{m}_{R}$ - mass-flow rate of the core material, $C_{\text {rot }}$ - dimensionless core rotation rate, $C_{N}$ - heat capacity rate on the compressed air side, $c_{R}$ - specific heat capacity of the core material, $\dot{m}_{N}$ - air mass flow rate, $i_{N o}, i_{n i}$ - outlet and inlet specific enthalpy on the compressed air side, respectively, $T_{N o}, T_{N i}$ - outlet and inlet temperature on the compressed air side, respectively. 


\subsection{Number of Transfer Units $(N T U)$}

The number of transfer units can be obtained from the following equation (Beck and Wilson, 1996)

$$
N T U=\frac{1}{C_{N}} \frac{1}{\frac{1}{(h A)_{X}}+\frac{1}{(h A)_{N}}}
$$

where

$$
\begin{array}{lrl}
(h A)_{X}=\left(\frac{\Delta P}{P}\right)_{X} \frac{C_{X} R \bar{T}_{X}}{\bar{U}_{X}^{2}} & C_{X}=\frac{\dot{m}_{X}\left(i_{X o}-i_{X i}\right)}{T_{X o}-T_{X i}} \\
(h A)_{N}=(h A)^{\prime}(h A)_{X} & (h A)^{\prime}=\frac{\bar{k}_{N}}{\bar{k}_{X}} V^{\prime}
\end{array}
$$

where $(h A)_{X},(h A)_{N}[\mathrm{~W} / \mathrm{K}]$ are convective conductances associated with the core passages on the exhaust side and on the compressed air side, respectively, $(\Delta P / P)_{X}$ - dimensionless pressure drop across the exhaust side, $C_{X}$ - heat capacity rate on the exhaust side, $\bar{T}_{X}-$ average temperature on the exhaust side, $\dot{m}_{X}$ - exhaust mass flow rate, $i_{X o}, i_{X i}$ - outlet and inlet specific enthalpy on the exhaust side, respectively, $T_{X o}, T_{X i}-$ outlet and inlet temperature on the exhaust side, respectively, $(h A)^{\prime}$ - convective conductance ratio, $\overline{k_{N}} \overline{k_{X}}$ - average thermal conductivity on the compressed air side and on the exhaust side, respectively.

\subsection{Regenerator effectiveness}

In this work, the regenerator effectiveness using the $\varepsilon-N T U$ method is represented as a function of four non-dimensional numbers, $\varepsilon=f\left(N T U, C^{*}, C_{r}^{*}, \lambda\right)$, and estimated as follows (Shah and Sekulic, 2003)

$$
\varepsilon=\varepsilon_{c f}\left[1-\frac{1}{9\left(C_{r}^{*}\right)^{1.93}}\right]\left(1-\frac{C_{\lambda}}{2-C^{*}}\right) \quad \varepsilon_{c f}=\frac{1-\exp \left[-N T U\left(1-C^{*}\right)\right]}{1-C^{*} \exp \left[-N T U\left(1-C^{*}\right)\right]}
$$

and

$$
\begin{aligned}
& C_{\lambda}=\frac{1}{1+N T U(1+\lambda \phi) /(1+\lambda N T U)}-\frac{1}{1+N T U} \\
& \phi=\sqrt{\frac{\lambda N T U}{1+\lambda N T U}} \quad \text { for } \quad N T U \geqslant 3
\end{aligned}
$$

where the heat capacity ratio $C^{*}$, the exchanger heat capacity ratio $C_{r}^{*}$ and the core conduction parameter $\lambda$ are defined as

$$
C^{*}=\frac{C_{\min }}{C_{\max }} \quad C_{r}^{*}=\frac{m_{R} c_{r} S_{\text {core }}}{C_{\min }} \quad \lambda=\frac{k_{R} A_{k, t}}{L C_{\min }}
$$

where

$$
A_{k, t}=A_{f r}(1-p) \quad A_{f r}=\frac{\pi}{4}\left(D_{o}^{2}-D_{i}^{2}\right)(1-S C)
$$

and $A_{k, t}$ is the total conduction area, $A_{f r}$ is the frontal area of exchanger. 


\section{Objective function and constraints}

The properties of the core material and gas properties are tabulated in Table 1. Eight design parameters are selected in this work as variables to optimize the effectiveness as the objective function in a regenerator with fixed pressure drop. The range of variation of decision variables for selecting the optimum design parameters are listed in Table 2. Next, two algorithms (GA and Firefly) start to optimize the design parameters by choosing different values of the decision variables. A population size of 600 to supply a good diversity of the population and the maximum number of generations of 2000 are set for all optimization algorithms. The other specifications of GA and Firefly algorithms used in this work are tabulated in Table 3.

Table 1. Properties of the core material and gas

\begin{tabular}{|l|c|}
\hline Property & Value \\
\hline \hline$(\Delta P / P)_{X}$ & 0.02 \\
\hline$\rho_{R}$ & $7770 \mathrm{~kg} / \mathrm{m}^{3}$ \\
\hline$c_{R}$ & $460 \mathrm{~J} / \mathrm{kg} \mathrm{K}$ \\
\hline$k_{R}$ & $25 \mathrm{~W} / \mathrm{m} \mathrm{K}$ \\
\hline$T_{N i}$ & $458.34 \mathrm{~K}$ \\
\hline$T_{X i}$ & $890.82 \mathrm{~K}$ \\
\hline$T_{N o}$ & $869.2 \mathrm{~K}$ \\
\hline$T_{X o}$ & $504.7 \mathrm{~K}$ \\
\hline $\bar{k}_{N}$ & $0.05029 \mathrm{~W} / \mathrm{m} \mathrm{K}$ \\
\hline $\bar{k}_{X}$ & $0.05218 \mathrm{~W} / \mathrm{m} \mathrm{K}^{3}$ \\
\hline $\bar{\rho}_{X}$ & $0.5147 \mathrm{~kg} / \mathrm{m}^{3}$ \\
\hline
\end{tabular}

Table 2. Design parameters and corresponding ranges

\begin{tabular}{|l|c|}
\hline $\begin{array}{c}\text { Decision } \\
\text { variables }\end{array}$ & Range \\
\hline \hline$S C$ & $0.1-0.3$ \\
\hline$p$ & $0.8-0.87$ \\
\hline$V^{\prime}$ & $0.3-0.6$ \\
\hline$L[\mathrm{~m}]$ & $0.028-0.034$ \\
\hline$C_{r o t}$ & $2-5$ \\
\hline$D_{i}[\mathrm{~m}]$ & $2-2.5$ \\
\hline$\dot{m}_{X}[\mathrm{~kg} / \mathrm{s}]$ & $49-53$ \\
\hline$\dot{m}_{N}[\mathrm{~kg} / \mathrm{s}]$ & $44-48$ \\
\hline
\end{tabular}

\section{Results and discussion}

The effectiveness of the regenerator and the optimal variables calculated by GA and Firefly algorithms are listed in Table 4 and validated with the corresponding results from (Beck and Wilson, 1996). It can be observed that the results obtained by GA algorithm are very similar to the results obtained by Firefly algorithm and have slight differences as compared to the results obtained by RGT-OPT software (Beck and Wilson, 1996). The dimensions of the regenerator are calculated by specifying the design parameters and summarized in Table 5 .

In the present study, the effect of design parameters of $p, C_{r o t}, S C$ and $V^{\prime}$ on mass of the core is numerically investigated through fixing each of these parameters, while the other seven design parameters are selected as variables to optimize the effectiveness. 
Table 3. Specifications of GA and Firefly algorithms

\begin{tabular}{|l|c|}
\hline \multicolumn{2}{|c|}{ Firefly } \\
\hline \hline Light absorption coefficient & 1 \\
\hline Attraction coefficient base value & 2 \\
\hline Mutation coefficient & 0.2 \\
\hline Mutation coefficient damping ratio & 0.98 \\
\hline \multicolumn{2}{|c|}{ GA } \\
\hline \hline Mutation function & adaptive feasible \\
\hline Crossover function & two point \\
\hline Crossover fraction & 0.8 \\
\hline Population function & feasible population \\
\hline
\end{tabular}

Table 4. Comparison between design variables and corresponding results by Beck and Wilson (1996)

\begin{tabular}{|l|c|c|c|}
\hline $\begin{array}{c}\text { Decision } \\
\text { variables }\end{array}$ & $\begin{array}{c}\text { Beck and } \\
\text { Wilson (1996) }\end{array}$ & GA & Firefly \\
\hline \hline$S C$ & 0.1 & 0.104100 & 0.1 \\
\hline$p$ & 0.8 & 0.801515 & 0.8 \\
\hline$V^{\prime}$ & 0.3 & 0.301091 & 0.3 \\
\hline$L[\mathrm{~m}]$ & 0.02883 & 0.0282952 & 0.028 \\
\hline$C_{r o t}$ & 3.0 & 2.030487 & 2.002312 \\
\hline$D_{i}[\mathrm{~m}]$ & 2.0 & 2.005670 & 2 \\
\hline$\dot{m}_{X}[\mathrm{~kg} / \mathrm{s}]$ & 49.31 & 49.001140 & 49 \\
\hline$\dot{m}_{N}[\mathrm{~kg} / \mathrm{s}]$ & 47.87 & 47.999771 & 47.954001 \\
\hline$\varepsilon$ & 0.95 & 0.972184 & 0.972349 \\
\hline
\end{tabular}

Table 5. Comparison of design results for different algorithms

\begin{tabular}{|l|c|c|c|}
\hline $\begin{array}{c}\text { Decision } \\
\text { variables }\end{array}$ & $\begin{array}{c}\text { Beck and } \\
\text { Wilson (1996) }\end{array}$ & GA & Firefly \\
\hline \hline$A_{X}\left[\mathrm{~m}^{2}\right]$ & 17.58 & 17.467517 & 17.5002 \\
\hline $\mathrm{AN}\left[\mathrm{m}^{2}\right]$ & 5.274 & 5.259328 & 5.250060 \\
\hline$A_{S}\left[\mathrm{~m}^{2}\right]$ & 2.540 & 2.640783 & 2.527806 \\
\hline$A_{\text {tot }}\left[\mathrm{m}^{2}\right]$ & 25.40 & 25.367629 & 25.278066 \\
\hline$V_{R}\left[\mathrm{~m}^{3}\right]$ & 0.7322 & 0.717784 & 0.707785 \\
\hline$m_{R}[\mathrm{~kg}]$ & 1138 & 1106.984449 & 1099.899236 \\
\hline$D_{o}[\mathrm{~m}]$ & 2.058 & 2.062261 & 2.056 \\
\hline$\omega[\mathrm{m}]$ & 3.984 & 3.969961 & 3.967583 \\
\hline$\tau_{\text {rot }}[\mathrm{s}]$ & 3.417 & 4.898704 & 4.940551 \\
\hline$S_{\text {core }}[\mathrm{m} / \mathrm{s}]$ & 1.865 & 1.304404 & 1.289562 \\
\hline$\omega_{S}[\mathrm{~m}]$ & 0.3187 & 0.332595 & 0.318557 \\
\hline$V_{S}\left[\mathrm{~m}^{3}\right]$ & 0.07322 & 0.074721 & 0.070778 \\
\hline$L_{S}[\mathrm{~m}]$ & 8.026 & 7.996513 & 7.991166 \\
\hline
\end{tabular}

The mass of the core is decreasing with growing core porosity except for the core porosity of 0.82 and 0.86 as is shown in Fig. 3. This is due to selection of $L=0.032$ in the optimization process for these core porosities, whereas $L=0.028$ is chosen for other core porosities. 


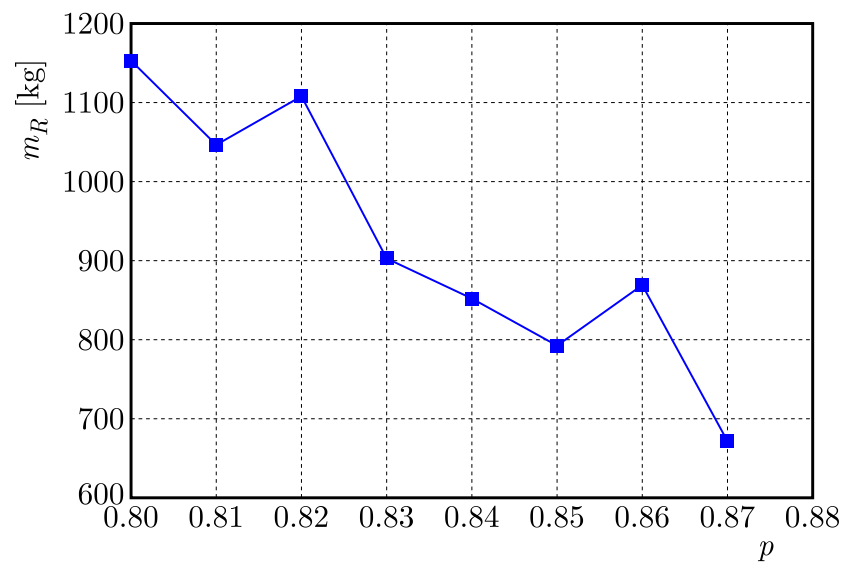

Fig. 3. Variation of mass of the core with core porosity

A heat exchanger designer must select core-rotation rates in the range $2 \leqslant C_{\text {rot }} \leqslant 5$ (Beck, 1995). To identify the appropriate selection of $C_{r o t}$, the influence of fixed values of $C_{\text {rot }}$ on mass of the core is evaluated by considering the other seven design parameters as variables. As can be seen in Fig. 4, the maximum mass of the core at $C_{\text {rot }}=3.5$ with $L=0.0338 \mathrm{~m}$ is equal to $1311.92 \mathrm{~kg}$ and the minimum mass of the core at $C_{\text {rot }}=2.5$ with $L=0.0284 \mathrm{~m}$ is equal to $1101.07 \mathrm{~kg}$. It is also not appropriate to select $C_{\text {rot }}$ of more than 3 in the rotary-regenerator design process.

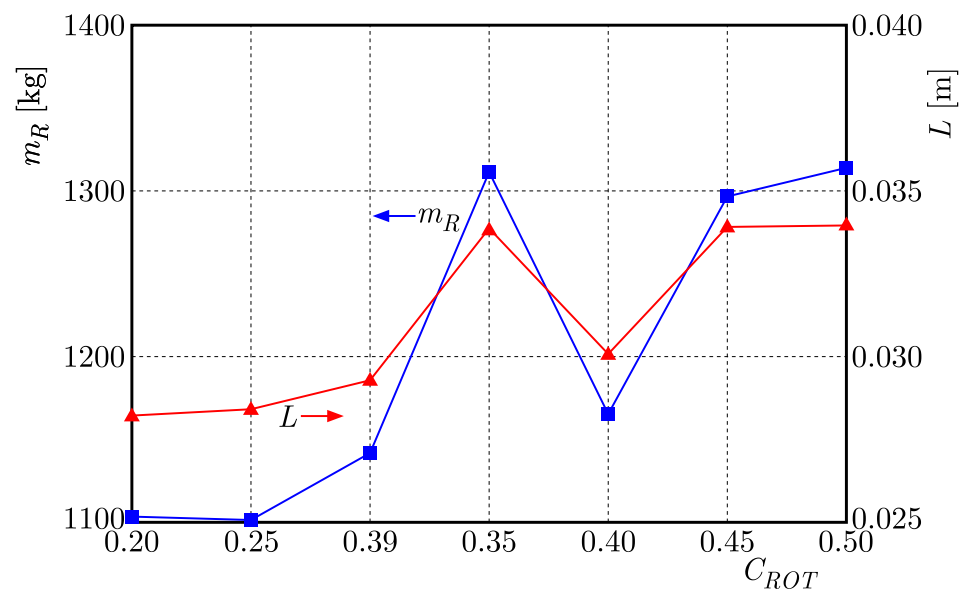

Fig. 4. Variations of mass of the core and core thickness with the dimensionless core rotation rate

Figure 5 shows that the total core volume is increasing with the increasing seal coverage to a maximum of $1.015 \mathrm{~m}^{3}$ for $S C=0.25$. This is due to setting $V^{\prime}=0.55$ in the optimization process for $S C=0.25$, whereas $V^{\prime}$ is selected at about 0.3 for other seal coverages. At this seal coverage, the maximum value of mass of the core is equal to $1517.22 \mathrm{~kg}$, which is approximately $38.65 \%$; therefore, it is higher than $S C=0.1$. The results show that despite increasing the total core volume with increasing $S C$ from 0.1 to 0.15 , mass of the core decreases (and not increases) with increasing core porosity from 0.8015 to 0.8158 .

Figure 6 shows that the total core volume and mass of the core are increasing with the increasing core volume ratio to a maximum of $0.8744 \mathrm{~m}^{3}$ and $1324.10 \mathrm{~kg}$ for $V^{\prime}=0.6$, respectively. In this optimization process, other design parameters are approximately constant the variable core volume ratio. 


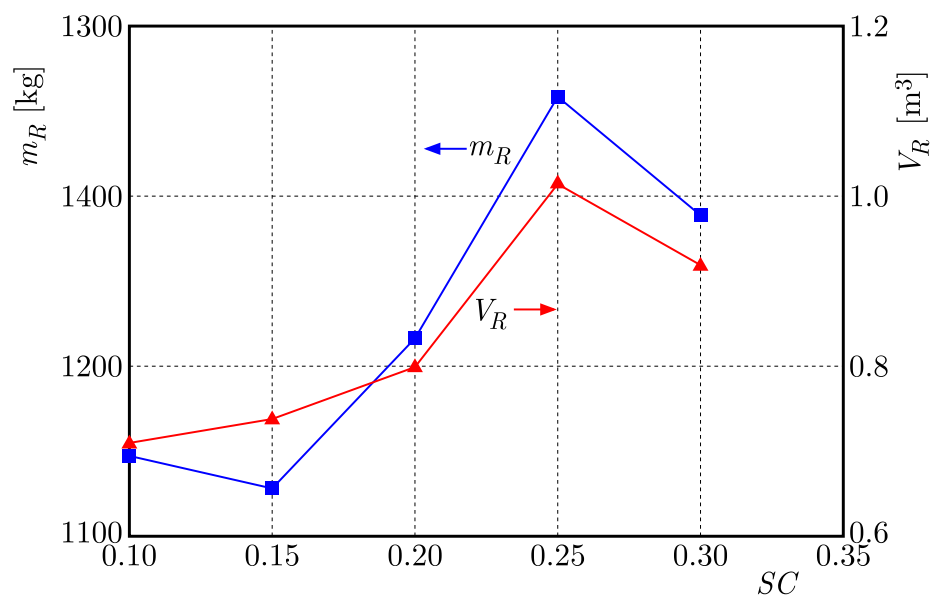

Fig. 5. Variations of mass of the core and the total core volume with the seal coverage

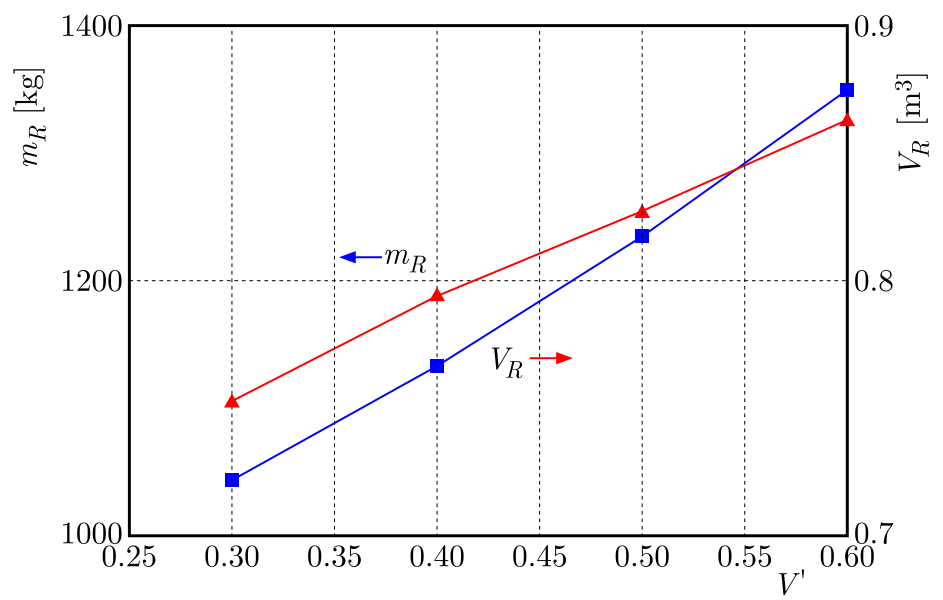

Fig. 6. Variations of mass of the core and the total core volume with the core volume ratio

\section{Conclusions}

- The core porosity, core volume ratio, core thickness, dimensionless core rotation rate, inner diameter of the core, air mass flow rate and exhaust mass flow rate are proposed as design variables to design and optimize a regenerator of a 20-MW power generation gas turbine with fixed pressure drop.

- The governing equations for design and optimization of the regenerator are evaluated; and GA and Firefly algorithms are applied to optimize the design variables by considering the effectiveness of the regenerator as the objective function.

- Dimensions of the regenerator are calculated by specifying the design variables in this work.

- Effects of change in the seal coverage, core porosity, core volume ratio and dimensionless core rotation rate are evaluated as important design parameters impacting size and mass of the core of the regenerator.

- Selection of all eight design parameters proposed as operating variables is necessary as optimization parameters to achieve the proper design of the regenerator.

\section{References}

1. Akbari A., Kouravand S., Chegini G., 2018, Experimental analysis of a rotary heat exchanger for waste heat recovery from the exhaust gas of dryer, Applied Thermal Engineering, 138, 668-674 
2. Alhusseny A., Turan A., 2016, An effective engineering computational procedure to analyse and design rotary regenerators using a porous media approach, International Journal of Heat and Mass Transfer, 95, 593-605

3. BECK D.S., 1995, A Compact Lightweight Gas-Turbine Regenerator, ASME

4. Beck D.S., Wilson D.G., 1996, Gas-Turbine Regenerators, Springer, Boston, MA

5. Chung H.J., Lee J.S., Baek C., Kang H., Kim Y., 2016, Numerical analysis of the performance characteristics and optimal design of a plastic rotary regenerator considering leakage and adsorption, Applied Thermal Engineering, 109, 227-237

6. Holland J.H., 1975, Adaptation in Natural and Artificial Systems, University of Michigan Press, Ann Arbor, Michigan; re-issued by MIT Press (1992)

7. Mioralli P.C., Ganzarolli M.M., 2013, Thermal analysis of a rotary regenerator with fixed pressure drop or fixed pumping power, Applied Thermal Engineering, 52, 187-197

8. Mohanty D. K., 2016, Application of firefly algorithm for design optimization of a shell and tube heat exchanger from economic point of view, International Journal of Thermal Sciences, 102, $228-238$

9. Özdemir K., Serincan M.F., 2018, A computational fluid dynamics model of a rotary regenerative heat exchanger in a flue gas desulfurization system, Applied Thermal Engineering, 143, 988-1002

10. Raja B.D., Jhala R.L., PATel V., 2016, Multi-objective optimization of a rotary regenerator using tutorial training and self-learning inspired teaching-learning based optimization algorithm (TS-TLBO), Applied Thermal Engineering, 93, 456-467

11. Raja B.D., Jhala R.L., PATel V., 2018, Thermal-hydraulic optimization of plate heat exchanger: A multi-objective approach, International Journal of Thermal Sciences, 124, 522-535

12. Raja B.D., Patel V., Jhala R.L., 2017, Thermal design and optimization of fin-and-tube heat exchanger using heat transfer search algorithm, Thermal Science and Engineering Progress, 4, 45-57

13. Rao R.V., Patel V.K., 2010, Thermodynamic optimization of cross flow plate-fin heat exchanger using a particle swarm optimization algorithm, International Journal of Thermal Sciences, 49, $1712-1721$

14. Rao R.V., Patel V.K., 2013, Multi-objective optimization of heat exchangers using a modified teaching-learning-based optimization algorithm, Applied Mathematical Modeling, 37, 1147-1162

15. SAnAye S., Jafari S., Ghaebi H., 2008, Optimum operational conditions of a rotary regenerator using genetic algorithm, Energy and Buildings, 40, 1637-1642

16. Sнah R.K., Sekulic D.P., 2003, Fundamentals of Heat Exchanger Design, John Wiley \& Sons, Inc.

17. Wang L., Bu Y., Li D., Tang C., Che D.F., 2019, Single and multi-objective optimizations of rotary regenerative air preheater for coal-fired power plant considering the ammonium bisulfate deposition, International Journal of Thermal Sciences, 136, 52-59

18. Wang S., Jian G., Xiao J., Wen J., Zhang Z., Tu J., 2018, Fluid-thermal-structural analysis and structural optimization of spiral-wound heat exchanger, International Communications in Heat and Mass Transfer, 95, 42-52

19. Wen J., Gu X., Wang M., Wang S., Tu J., 2017, Numerical investigation on the multi-objective optimization of a shell-and-tube heat exchanger with helical baffles, International Communications in Heat and Mass Transfer, 89, 91-97

20. Wu J., Liu S., Wang M., 2018, Process calculation method and optimization of the spiral-wound heat exchanger with bilateral phase change, Applied Thermal Engineering, 134, 360-368

21. YANG X.S., 2008, Nature-Inspired Metaheuristic Algorithms, Luniver Press 